\title{
Granular tumors of the central nervous system: A case series
}

\author{
Janese Trimaldi, Nicole D Riddle, Jeremy W Bowers, \\ Harry R van Loveren, Kondi Wong
}

\begin{abstract}
Introduction: Granular cell tumors of the central nervous system are rare tumors. To date, eight cases arising from cranial nerves have been reported. Granular cell tumors have also been found arising from the neurohypophysis and its stalk. Due to their rarity and histological similarity to other central nervous system (CNS) tumors with a granular appearance, they often pose a diagnostic conundrum. The differential diagnosis is surprisingly diverse and includes granular cell astrocytoma, infundibular granular cell tumor, spindle cell oncocytoma of the adenohypophysis, granular and oncocytic variants of pituitary adenoma, meningioma, pituicytoma and intrasellar schwannoma. Distinguishing between the CNS tumors with granular features is important because some tumors have an increased recurrence risk or a poor prognosis. Case Report: To highlight the histological features of granular lesions of the central nervous system, including the
\end{abstract}

Janese Trimaldi ${ }^{1}$, Nicole D Riddle ${ }^{2}$, Jeremy W Bowers ${ }^{3}$, Harry R van Loveren ${ }^{4}$, Kondi Wong ${ }^{1}$

Affiliations: ${ }^{1}$ Department of Pathology and Cell Biology, University of South Florida College of Medicine, Tampa, FL, USA; ${ }^{2}$ Department of Pathology, University of Texas Health Science Center, San Antonio, TX, USA; 3Department of Pathology, Moffitt Cancer Center, Tampa, FL, USA; ${ }^{4}$ Department of Neurosurgery, University of South Florida College of Medicine, Tampa, FL, USA Corresponding Author: Nicole D Riddle, MD., Department of Pathology University of Texas Health Science Center, 7703 Floyd Curl Dr, MC 7750 San Antonio, TX, USA; Ph: 210-567-3748; Fax: 210-567-2478; Email: nriddlemd@gmail.com

Received: 14 March 2012

Accepted: 07 May 2012

Published: 01 January 2013 immunohistochemical profile and electron microscopic depiction, we review two cases each with a similar granular histology and a different final diagnosis. Conclusion: Thorough online literature search revealed several cases of granular cell lesions of the CNS, however, oftentimes the diagnosis is difficult to come by and the differential is long. Conclusion: Granular cell tumor and its variants, though uncommon, must be included in the differential diagnosis of CNS lesions.

Keywords: Granular, Tumors, Central nervous system (CNS)

$$
* * * * * * * * *
$$

Trimaldi J, Riddle ND, Bowers JW, Loveren HRv, Wong K. Granular tumors of the central nervous system: A case series. International Journal of Case Reports and Images 2013;4(1):1-6.

$* * * * * * * * *$

doi:10.5348/ijcri-2013-01-247-CS-1

\section{INTRODUCTION}

Granular cell lesions of the central nervous system (CNS) are rather uncommon and may pose a diagnostic challenge. Granular histology may be present as the main characteristic of a neoplasm or as a variation in a number of benign and malignant lesions. The differential diagnosis must always include a true granular cell tumor when granular morphology is identified, especially when it encompasses a majority of the lesion. The differential diagnosis of a CNS granular cell tumor is widely varied and includes infundibular granular cell tumor, granular/oncocytic variants of pituitary adenoma, meningioma, pituicytoma and intrasellar schwannoma, as well as spindle cell 
oncocytoma of the adenohypophysis, which may be prone to recur and grow despite adjuvant therapy, and granular cell astrocytoma, which has a poor prognosis.

\section{CASE REPORT}

Case 1: A 37-year-old male presented with a history of depression, fatigue, and decreased libido for two years. Magnetic resonance imaging (MRI) was performed revealing a left-sided pituitary mass that was enlarging the sella with suprasellar extension. Postcontrast images demonstrated an intensely enhancing mass in the right middle cranial fossa that was hypointense on T2-weighted images and isointense to adjacent gray matter on T1-weighted images (Figure 1). It was centered in Meckel's cave with involvement of the cisternal segment of the trigeminal nerve. There was distal extension of the mass along the inferior alveolar branch of $\mathrm{V}_{3}$ into the mandibular foramen. The right side of the pituitary gland appeared to be uninvolved. Surgical removal was performed through a transnasal endoscopic approach and yielded a $1.4 \times 0.4 \times 0.1 \mathrm{~cm}$ tumor. Frozen section analysis revealed a granular epithelial cell neoplasm. The differential diagnosis at that time included: pituitary adenoma, xanthoma, infundibular granular cell tumor, langerhans cell histiocytosis, hemangioblastoma and granular cell astrocytoma.

Routine histological examination with hematoxylin and eosin (H\&E) stained sections revealed diffuse,

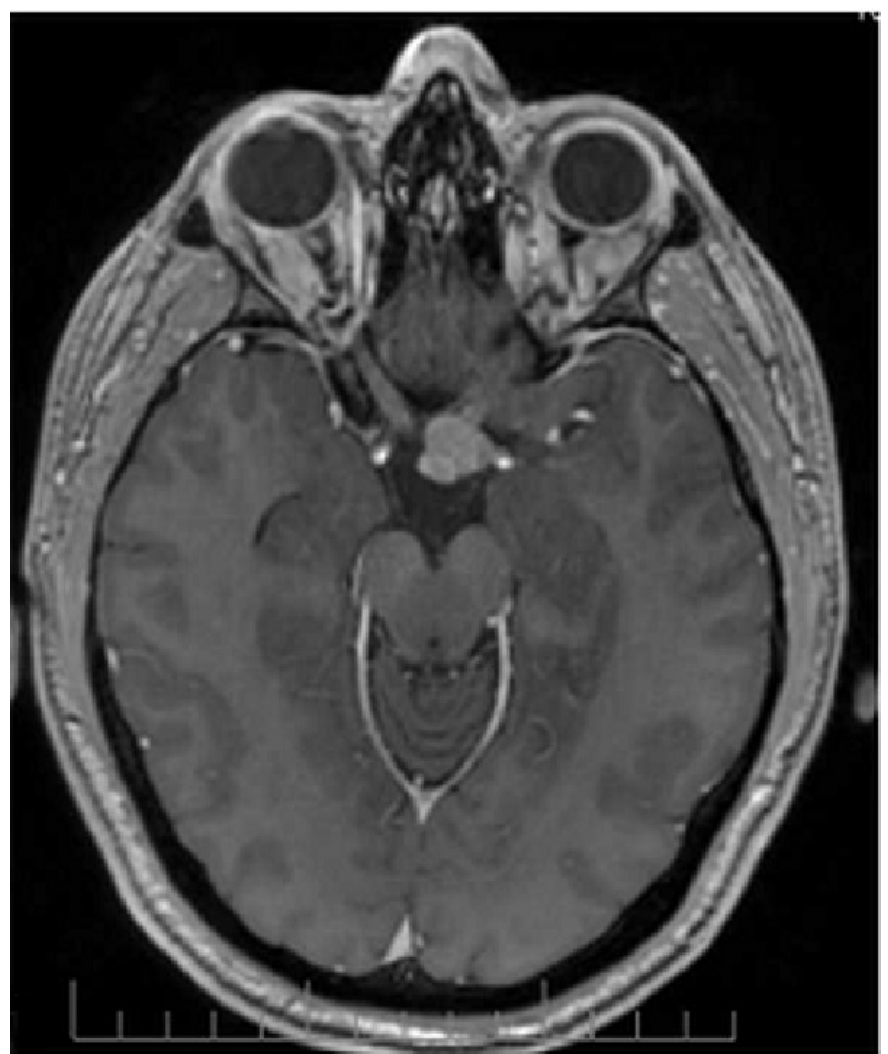

Figure 1: Magnetic resonance imaging scan of pituitary mass with some suprasella extension. The mass can be seen overlying the optic chiasm.

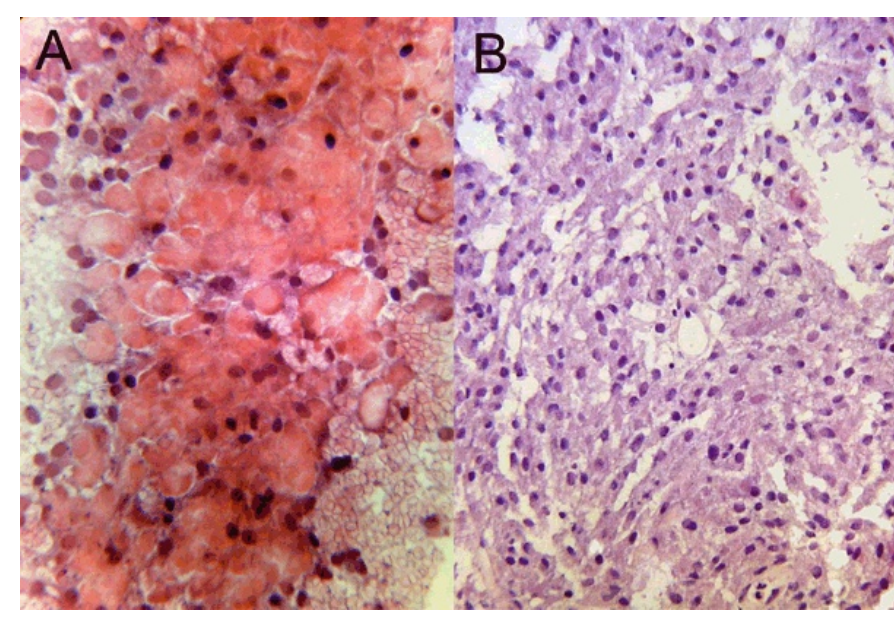

Figure 2: Monotonous cells with abundant granular cytoplasm (H\&E, x200).

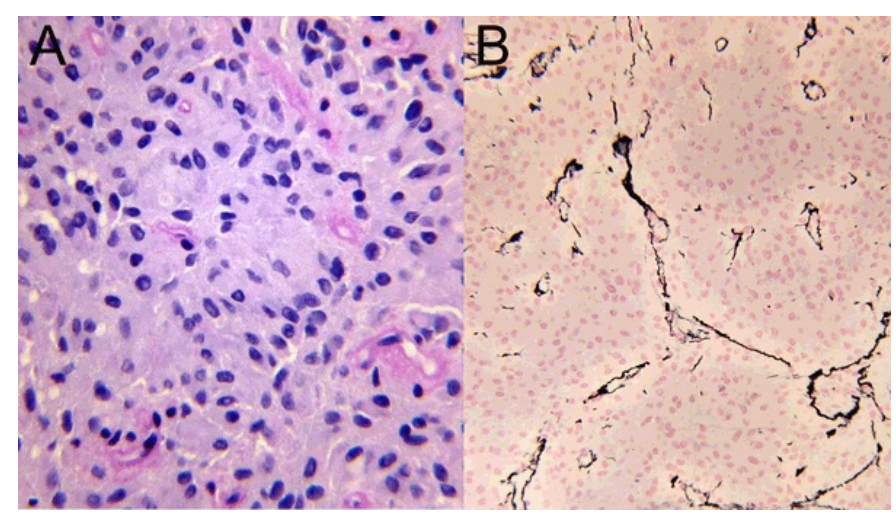

Figure 3: PAS with diastase showing abundant eosinophilic granular cytoplasm (PAS with diastase, x200).

densely granulated, eosinophilic cells (Figure 2). Special staining for PAS was also positive (Figure 3). Immunohistochemical studies showed the tumor cells to be weakly positive for prolactin and strongly synaptophysin positive. The tumor cells were nonreactive for CD68, inhibin, S100, chromogranin; as well as pituitary markers such as ACTH, FSH, LH, GH, and TSH. Pancytokeratin and GFAP were also negative. Complete disruption of the native lobular reticular architecture was evident on reticulin stain, characteristic of a pituitary adenoma. A diagnosis of pituitary adenoma with granular cell morphology, and evidence of prolactin expression was given.

Case 2: A 54-year-old woman with a history of Bell's palsy one year prior with recurrence nine months later, presented with numbness primarily in the third division of the right trigeminal nerve.

MRI scan showed a tumor homogeneously enhancing in the gasserion ganglion with an extension into the foramen ovale (Figure 4). A right temporal craniotomy and zygomatic osteotomy was performed, and the foramen ovale was opened for resection of a $6.1 \times 4.3 \times 1.2 \mathrm{~cm}$ tan-brown mass with multi-nodular areas. Frozen section analysis suggested a possible ganglioneuroma. Following histological evaluation a 


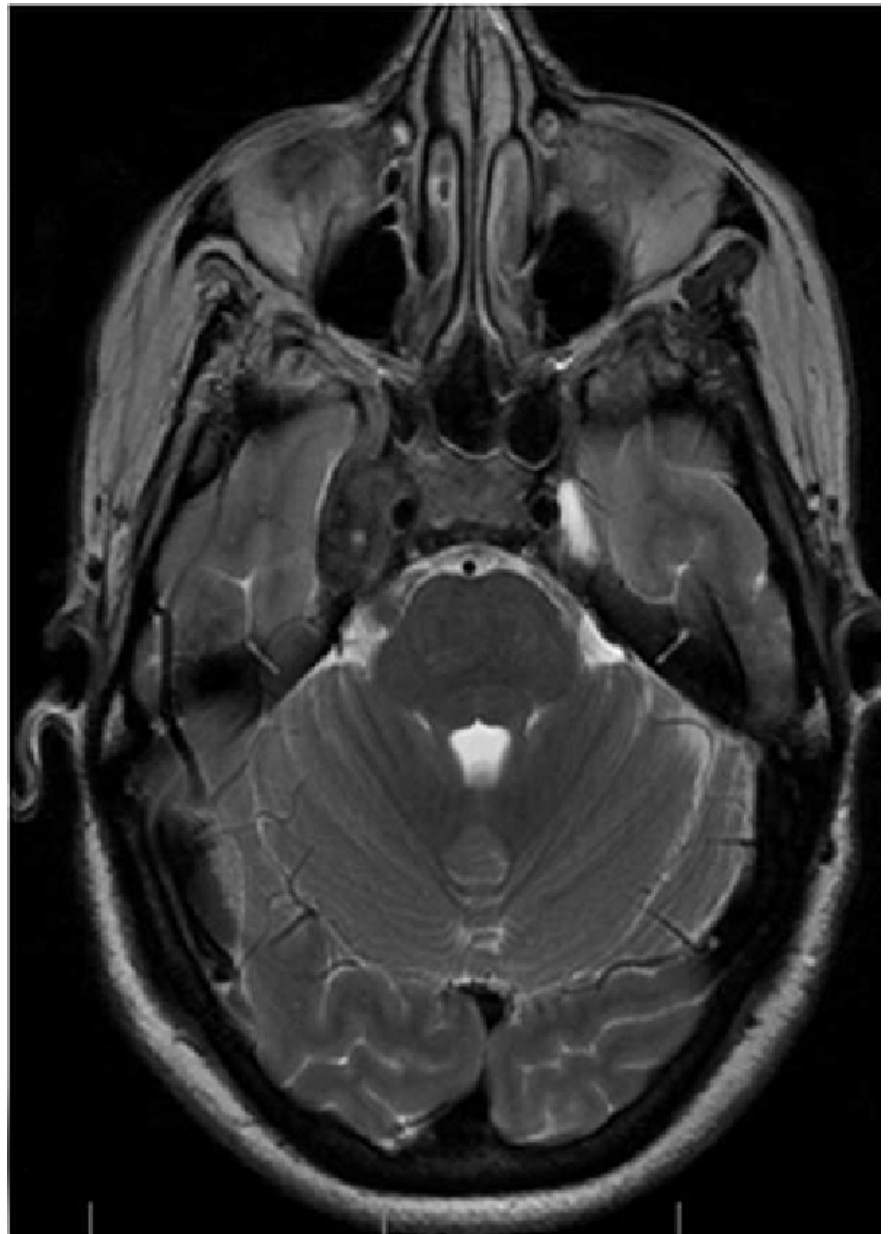

Figure 4: Magnetic resonance imaging scan showing a mass in the region of the gasserion ganglion.

diagnosis of granular cell tumor of the right trigeminal ganglion was rendered. Permanent section analysis revealed peripheral nerve and entrapped ganglion cells (trigeminal ganglion) infiltrated by round, spindled and epithelioid cells with abundant, granular, PAS-positive cytoplasm consistent with granular cell tumor (Figure 5). The tumor cells were strongly positive for CD 68 with abundant PAS positive cytoplasmic granules and strong reactivity to S100 (Figures 6 and 7). They were nonreactive for: synaptophysin, smooth muscle actin, muscle specific actin, melan-A, myogenin, GFAP, smooth muscle myosin heavy, and desmin. Ki67 demonstrated moderate proliferative activity as well as moderate amounts of reticulin collagen and neuron specific enolase (not shown). Electron microscopy demonstrated tumor cell cytoplasm filled and expanded with dark, granular lysosomes, characteristic of granular cell tumor (Figure 8).

\section{DISCUSSION}

A number of granular or similarly oncocytic tumors have remarkably similar histomorphology on initial staining with hematoxylin and eosin. Differing intracranial locations may be helpful at times for

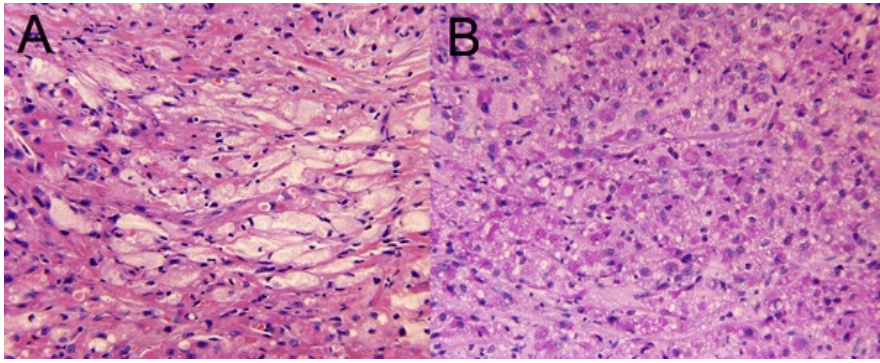

Figure 5: Peripheral nerve and entrapped ganglion cells infiltrated by spindled and epithelioid cells with abundant granular cytoplasm (H\&E, 200x).

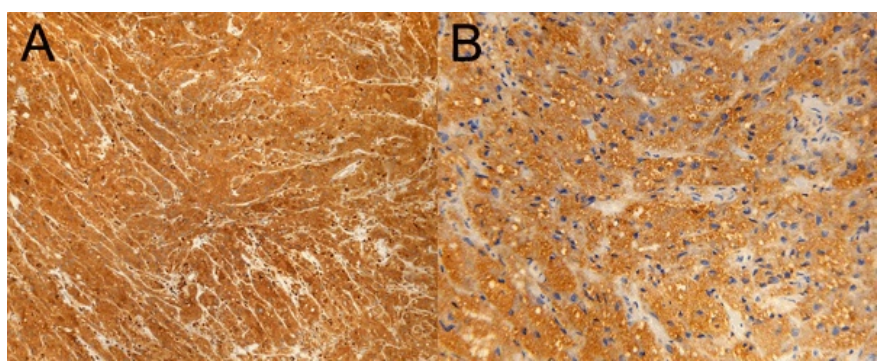

Figure 6: Lysomal granules strongly positive for CD68.

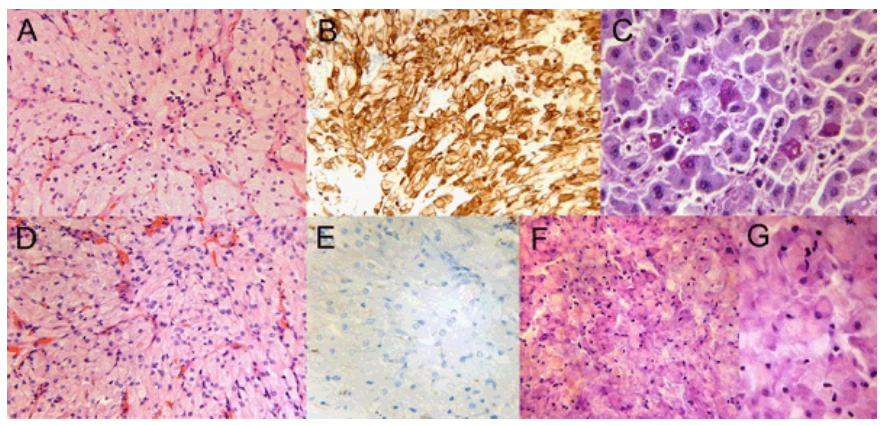

Figure 7: PAS with diastase showing abundant eosinophilic granular cytoplasm (PAS with diastase, 200x).
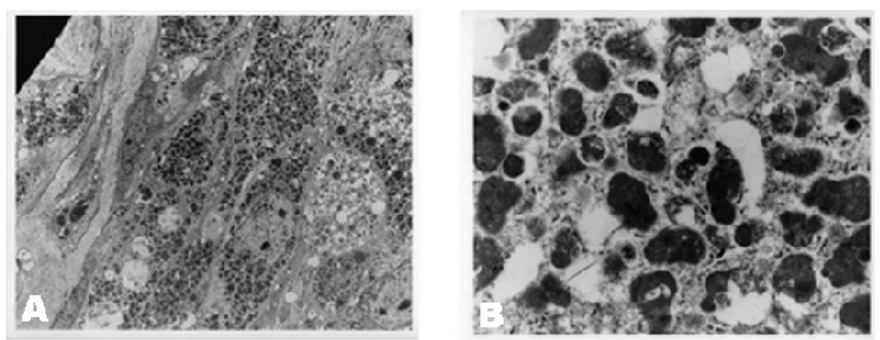

Figure 8: (A) Tumor cells with cytoplasm filled and expanded with dark, granular lysosomes, (B) Lysosomal vacuoles containing membranous and electron dense material consistent with degenerating phagolysosomes.

diagnosis, but at other times they may be misleading. Tumors containing granular cells can present in two forms: (i) as a "pure" form composed entirely of granular cells ("granular cell tumor"), (ii) or as a focal change that occurs in a neoplasm of a recognizable cell type [1]. In the latter form, one theory considers granular cell change to be a degenerative phenomenon 
[2]. The hypothesis is that the granular cell phenotype seems to be not specific of a certain tumor type, but rather a peculiar change characterized by an increase in intracellular lysosomes.

Reported CNS tumors with granular cell or oncocytic change include: astrocytoma, medulloblastoma, ganglioglioma, glioblastoma, meningioma, schwannoma, ependymoma, oligodendroglioma, neurofibroma, anterior and posterior pituitary [2-7]. Spindle cell oncocytoma, granular cell astrocytoma, and pituicytoma are distinct entities and possibly the infundibular granular cell tumor as well. Morphology on hematoxylin and eosin stain and special stains alongside tumor immunophenotype are a valuable aide in pathologic evaluation and distinguishing the different tumor types.

There are distinguishing characteristics of different tumor types. Granular cell astrocytomas are GFAP reactive in more than $95 \%$ cases [19] and have a poor prognosis. Spindle cell oncocytomas of the adenohypophysis have S100 reactivity, but are negative for neuroglial markers and CD68 because they are filled with mitochondria, not phagolysosomes. Spindle cell oncocytomas are reactive for TTF-1 (thyroid transcription factor), but negative for thyroglobulin. Meningiomas are generally EMA (epithelial membrane antigen) reactive, at least focally, with a lobular reticulin pattern and meningeal pattern on ultrastructure. Granular/oncocytic pituitary adenomas lose the native lobular reticulin architecture of the pituitary gland and are reactive for neuroendocrine markers. Intrasellar schwannoma may have granular cytoplasm, but can be distinguished by the dense pericellular basal lamina on reticulin staining, diffuse S100 staining and non reactivity for other neuroglial markers. Electron microscopy shows a profuse basal laminar or basement membrane pattern with long spaced collagen or "Luse bodies" [20].

Conventional granular cell tumors are similar and differ by primary location and possibly cell of origin.

Eight cases of cranial nerve granular cell tumors have been reported in literature arising from the following nerves: vagus, oculomotor, abducens, optic, facial; and an additional three arising from the trigeminal nerve [8-15]. Of the four arising from the trigeminal ganglion, two were reported as confined to Meckel's cave, while one reported the tumor originating from the brain stem and extending into Meckel's cave [13-15]. All patients experienced symptoms of trigeminal neuralgia. All masses were composed of clusters or nests of cells, most polyhedral, with round nuclei, separated by connective tissue ranging from dense strands of collagen to delicate reticulin fibers. Tumor in our case was non-reactive for synaptophysin and GFAP, helping to rule out this entity in our differential diagnoses.

Granular cell change occurs as a cell accumulates lysosomes and phagosomes. There are numerous types of cytoplasmic accumulations that result in distinctive cell morphologies which correlate with the type of material that is being increased. Often a certain type of accumulated material favor a certain cell type. For example, clear cell change is usually due to glycogen accumulation, which is easily seen with a PAS stain with diastase digestion. Epithelial cells are the primary type of cell involved. Cytoplasmic vacuolization that leads to indentation of the nuclear membrane is due to lipid containing vacuoles, and is usually seen in sebaceous gland cells, adrenal cortex fasciculata cells, lipoblasts or adipose tissue neoplasms. In addition to phagosomes and lysosomes, other types of material such as neurosecretory granules or mast cell granules can lead to a granular appearance of the cytoplasm. In granular cell tumors, toluidine blue semithin sections of epon embedded tissue show cytoplasm filled with densely staining, but variegated vacuolar material that prove to be degenerated phagolysomes on electron microscopy [16].

Granular cell tumors may arise in the neurohypophysis or infundibulum of the pituitary gland. They have also been referred to as choristomas (microscopic nodules in the infundibulum) or myoblastomas. They show a preference for the stalk, are usually suprasellar and composed of nests of large, eosinophilic cells with abundant granular cytoplasm due to high lysosomal content. Most commonly, they are an incidental finding, usually at autopsy, composed of small, round, eosinophilic, infundibular nodules. Their origin is presumed to be the pituicyte-a specialized type of glial cell or modified astrocyte of the neurohypophysis [1]. Electron microscopy shows pituicytes to possess variable amounts of electron dense lysosomes, identical to those found in granular cell tumors. Hence, a newly described tumor, the pituicytoma, may possibly be related. Isolated or clusters of granular cells are a normal part of the histology of the neurohypophysis. It is rare for these microscopic nodules to enlarge enough to become symptomatic. When they do, they are usually suprasellar, discrete, and show intense heterogenous or homogenous enhancement with contrast. Common symptoms, including visual acuity deficits, or rarely, endocrine deficiency are usually the result of stalk compression. They show a predilection for adult females. Grossly, the tumor is lobulated, soft but rubbery (firmer than an adenoma) and very vascular, with a gray-yellow cut surface that usually lacks necrosis, cystic degeneration or invasion of surrounding structures. The tumor cells are polygonal, with small nuclei containing evenly dispersed chromatin and inconspicuous nucleoli, low mitosis/proliferation, and can grow in sheets, nodules, or in a spindled/fascicular pattern. The abundant cytoplasm contains granules that are diastase resistant with PAS staining. "Atypical" tumors show increased mitosis (up to 5/10 HPF, and Ki67 index of $7 \%$ ), nuclear pleomorphism, prominent nucleoli and multi-nucleation. The significance of this difference is unknown. Giant cell tumors (GCTs) are positive for: CD68, S100, alpha-1-antitrypsin, alpha-1antichymotrypsin, and cathepsin $\mathrm{B}$; and negative for neurofilament proteins, cytokeratins, chromogranin A, synaptophysin, desmin, smooth muscle actin and pituitary hormones. Though most are negative for glial 
neural filament protein (GFAP), some variable reactivity has been reported. A presumed lineage from pituicytes may explain the conflicting results of IHC since there are different types of pituicytes. Electron microscopy demonstrates phagolysosomes with unevenly distributed electron dense material and membranous debris. Neurosecretory granules are absent. Most are slow growing, non-invasive and clinically benign [17].

Granular cell astrocytomas (GCA) are infiltrative neoplasms and ill-defined. They are considered an aggressive variant (WHO grade 3) despite the fact that they are cytologically bland with few mitosis. The majority are found in cerebral hemispheres. Since they are associated with high grade astrocytomas, they display ring enhancement on imaging. Their cytoplasm, like other granular cell neoplasms, contains PAS positive, diastase resistant granules that often create an eccentric nucleus. Some tumor cells display a clear central cytoplasmic area and the granules accumulate at the periphery beneath the cell membrane. Granular cell astrocytomas are positive for CD68, EMA, and S100 in the majority of cases. GFAP is positive in over $95 \%$ of tumors $(18,19,21)$. The malignant nuclei are larger and courser than normal astrocytes, but are not as hyperchromatic or pleomorphic as in glioblastoma (WHO grade 4). The granular cell component can either be mixed with an otherwise typical diffuse astrocytoma or be the exclusive cell type in a lesion. Diagnosis may be particularly difficult in the diffuse exclusive cases and they are often mistaken for non-neoplastic processes such as infarcts or demyelinating diseases or GCTs of the infundibulum. Making this distinction, however, is paramount, as GCA's have a poor prognosis, whereas, granular cell tumor of the neurohypophysis is a benign, slowly progressive tumor without an invasive growth pattern

\section{CONCLUSION}

Granular cell lesions of the central nervous system are very rare. However, granular histology may be seen in a vast array of benign and malignant lesions. Histomorphology on hematoxylin and eosin stain and special stains with tumor immunophenotype can be a helpful aid in distinguishing the various tumor types. The differential of a granular cell tumor must always be included when granular cell morphology is present. Also, a granular cell astrocytoma must be ruled out due to prognostic implications.

$* * * * * * * * *$

\section{Author Contributions}

Janese Trimaldi - Conception and design, Acquisition of data, Drafting the article, Final approval of the version to be published

Nicole D Riddle - Conception and design, Acquisition of data, Analysis and interpretation of data, Drafting the article, Final approval of the version to be published
Jeremy Bowers - Conception and design, Acquisition of data, Critical revision of the article, Final approval of the version to be published

Harry Van Loveren - Acquisition of data, Drafting the article, Critical revision of the article, Final approval of the version to be published

Kondi Wong - Conception and design, Analysis and interpretation of data, Critical revision of the article, Final approval of the version to be published

\section{Guarantor}

The corresponding author is the guarantor of submission.

\section{Conflict of Interest}

Authors declare no conflict of interest.

\section{Copyright}

(C) Janese Trimaldi et al. 2013; This article is distributed under the terms of Creative Commons Attribution 3.0 License which permits unrestricted use, distribution and reproduction in any means provided the original authors and original publisher are properly credited. (Please see www.ijcasereportsandimages.com/copyright-policy.php for more information.)

\section{REFERENCES}

1. Cremonini A, Kuhn E, De Biase P, Franchi A. Welldifferentiated chondrosarcoma of the humerus with prominent granular cell component: a hitherto unreported occurrence. Int $J$ Surg Pathol 2006;14(2):147-54.

2. Geddes JF, Thom M, Robinson S, Revesz T. Granular cell change in astrocytic tumors. Am J Surg Pathol 1996 January;20(1):55-63.

3. Rickert $\mathrm{CH}$, Kuchelmeiser K, Gullotta F. Morphological and immunohistochemical characterization of granular cells in nonhypophyseal tumours of the central nervous system. Histopathology 1997;30(5):464-71.

4. Yang KH, Lee MC, Lee YS, et al. Ependymoma with granular cell changes: A case report. Presented at the meeting of American Association of Pathologists, Vancouver, BC, June 1996.

5. Takei Y, Mirra SS, Miles ML. Eosinophilic granular cells in oligodendrogliomas. An ultrastructural study. Cancer 1976;38(5):1968-76.

6. Muller W, Dahmen HG. A combined neurofibroma granular cell tumor of the middle cranial fossa. Pathol Res Pract 1978;163(4):378-6.

7. Tomita T, Gates E. Pituitary adenomas and granular cell tumors. Incidence, cell type, and location of tumor in 100 pituitary glands at autopsy. Am J Clin Pathol 1999;111(6):817-25.

8. Budzilovich GN. Granular cell "myoblastoma" of vagus nerve. Acta Neuropathol. 1968;10(2):162-5.

9. Inci S, Gulsen S, Soylemezoglu F, Kansu T, Ozgen T. Intracavernous granular cell tumor. Surg Neurol 2004;61(4):384-90.

10. Ogata S, Shimazaki H, Aida S, Miyazawa T, Tamai S. Giant intracranial granular-cell tumor arising from the abducens. Pathology International 2001;51(6):481-6. 
11. Muller W, Dahmen HG. Granular cell tumor of the optic nerve. Albrecht Von Graefes Arch Klin Exp Ophthalmol 1978;207(3):181-8.

12. May M, Beckford NS, Bedetti CD. Granular cell tumor of facial nerve diagnosed at surgery for idiopathic facial nerve paralysis. Otolaryngol Head and Neck Surg 1985 February;93(1):122-6.

13. Chimelli L, Symon L, Scaravilli F. Granular cell tumor of the fifth cranial nerve: further evidence for schwann cell origin. J Neuropathol Exp Neurol 1984;43(6):634-42.

14. Rao TV, Puri R, Reddy GN. Intracranial trigeminal nerve granular cell myoblastoma. Case report. J Neurosurg 1983;59(4):706-9.

15. Carvalho GA, Lindeke A, Tatagiba M, Ostertag H, Samii M. Cranial granular-cell tumor of the trigeminal nerve. Case report. J Neurosurg 1994;81(5):795-8.

16. Rosai J. The appearance, nature, and significance of cytoplasmic accumulations, as exemplified by the granular cell change. Int $\mathrm{J}$ Surg Pathol 2006;14(2):109-11.
17. AFIP Atlas of Tumor Pathology, Series 4. Tumors of the central nervous system. Burger PC, Scheithauer BW. The American Registry of Pathology 2007.

18. Claassen U, Kuntz G, Schmitt HP. Malignant intracerebral granular cell tumor reacts positively with anti-alpha-1-antichymotrypsin and the MB2 antibody: a clue to the histogenesis of the brain granular cell? Clin Neuropathol 1990;9(2):82-8.

19. Brat DJ, Scheithauer BW, Medina-Flores R, Rosenblum MK, Burger PC. Infiltrative astrocytomas with granular cell features (granular cell astrocytomas): a study of histopathologic features, grading, and outcome. Am J Surg Pathol 2002;26(6):750-7.

20. Luse SA. Electron microscopic studies of brain tumors. Neurology 1960;10:881-905.

21. Geddes JF, Thom M, Robinson S, Revesz T. Granular cell change in astrocytic tumors. Am J Surg Pathol 1996;20(1):55-63.
Access full text article on other devices

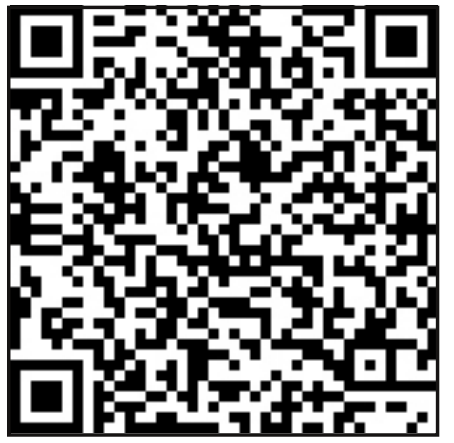

Access PDF of article on other devices

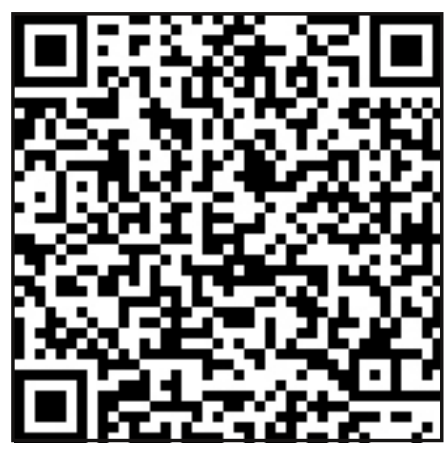

